\title{
A study of voltage regulation in microgrid using a DSTATCOM
}

\author{
Ziyaad H. Saleh ${ }^{1}$, Zaid H. Ali ${ }^{2}$, Raid W. Daoud ${ }^{3}$, Ahmed H. Ahmed ${ }^{4}$ \\ ${ }^{1}$ Department of Petroleum system control Engineering, College of Petroleum and Minerals, Tikrit University, Iraq \\ ${ }^{2,3,4}$ Department of Electrical Techniques, Hawija Technical Institute, Northern Technical University, Iraq
}

\begin{tabular}{l}
\hline \hline Article Info \\
\hline Article history: \\
Received Jan 20, 2020 \\
Revised Apr 1, 2020 \\
Accepted May 19, 2020 \\
\hline
\end{tabular}

Keywords:

Dampen power

DSTATCOM

Microgrid

Reliability

\begin{abstract}
A well-prepared abstract enables the reader to identify the basic content. This paper presents the solution of voltage fluctuations in urgent situations by providing voltage and reactive support from a distribution static synchronous compensator (DSTATCOM) in the grid. Also, it analyses the influences of DSTATCOM as a voltage controller and compares the system performance with and without DSTATCOM. The DSTATCOM is used in the study to maintain voltage in the microgrid (MG) to be around the rated value after Microgrid disturbance. A successful simulink model of the photovoltaic (PV) system and the proposed DSTATCOM are illustrated to work together as the Microgrid. Microgrids could provide unique resilience and reliability when the environment encountered with less water, higher temperatures, more frequent and harsh wildfires, and severe weather events. The proposed DSTATCOM was installed in different locations in the MG and the best location was chosen to achieve the goal of improved power quality and efficiency. In this paper, two scenarios are discussed with and without DSTATCOM. The simulation results show the difference between the MG with and without DSTATCOM and how the DSTATCOM can amplify power quality in the Microgrid. The proposed DSTATCOM has the capability to improve dampen power oscillations during transit events.
\end{abstract}

This is an open access article under the CC BY-SA license.

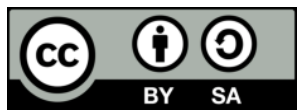

Corresponding Author:

Zaid H. Ali,

Department of Electrical Techniques,

Hawija Technical Institute,

Northern Technical University, Kirkuk, Iraq.

Email: Zaid.ali@uconn.edu

\section{INTRODUCTION}

Electrical power normally is generated in a large power plant located far away outside of cities. Then, the power is transmitted to the distribution system through transmission lines. Distribution Network consists of lower- voltage lines, which deliver the energy from substations to the customers. Recently, renewable energy systems have become prominent in electrical energy markets. Several renewable energy sources, such as solar and wind energy, play an important role in energy production [1-2]. Many developed countries have impartially reliable power generation [3-4]. The customers may encounter voltage sags in supply power large loads supplies. Customers are cautious of such voltage sags because these interruptions cause them economic losses. Consequently, the customer's request electricity with high power quality (PQ). Moreover, ED grids face transients such as voltage sags and swells and flickers. The MG has the possibility to solve issues arising from the generation penetration in distribution systems. Disturbances occur when the ideal system conditions change.

Many researches have been done on the DSTATCOM. A DSTATCOM for unbalanced load compensation was introduced to make less space demand and lower noise generation. DSTATCOM performance of a load 
compensator in steady and dynamic conditions for linear and nonlinear loads was presented [5]. Researchers compared the linear and nonlinear techniques of current regulation using a synchronous reference frame in DSTATCOM showing that in the nonlinear load case the THD in variable switching frame is lower than the fixed switching frame. The authors described and compared different PQ compensation devices like dynamic voltage restorer (DVR), SVC, and DSTATCOM to monitor and measure the power quality problems. A surveyed to solve power quality issues such as voltage flicker, voltage sag, and high harmonics has been made showing that the STATCOM can maintain great power quality in transmission and distribution grids. To improve power quality in distribution system with induction furnace loads many applications of DSTATCOM has been studied in [6-10] decreasing the current harmonics. To boost the power factor, the DSTATCOM has been used to provide reactive power compensation, voltage regulation, harmonics reduction, and power factor correction in the distribution system [11-13]. Controlling the voltage drop among the grid has been studied by several authors using renewable energy sources through injecting the reactive current into the grid [14-18].

This paper demonstrates the structure of DSTATCOM and its components. Also, it explains the working principals of the operation of DSTATCOM. The MG modelling is composed test feeder, PV system, and the DSTATCOM is showed in II. MATLAB/Simulink is used to verify the capability of DSTATCOM on improving power quality in the MG. The MG voltage issues is solved in III. Finally, the paper is concluded in IV.

\section{DSTATCOM MODELING}

The control system is crucial for DSTATCOM. In general, the control of the DSTATCOM is composed of four stages as shown in Figure 1. The first stage includes the measurement of the fundamental DC and AC currents and voltages using current transformers (CTs), potential transformers (PTs), and hall-effect sensors to collect data about the load and the system. Based on this data, in the second stage, methods like dq synchronous rotating axis transformation [19] and a-p stationary reference frame transformations [20] are used for decouple the real and reactive powers. Also, this stage generates the reference signal. The output voltage from the inverter is synchronized with the power grid voltage. The phase and frequency data of the essential positive sequence component of the grid voltage are collected by a phase locked loop (PLL). In the third stage, compensation commands are generated by using control techniques. The control methodology in this stage are classified into linear [21, 22], nonlinear [23] and special control methodologies [24-26]. In the fourth stage, the controller generates the gating signal for the solid-state devices of the VSC.

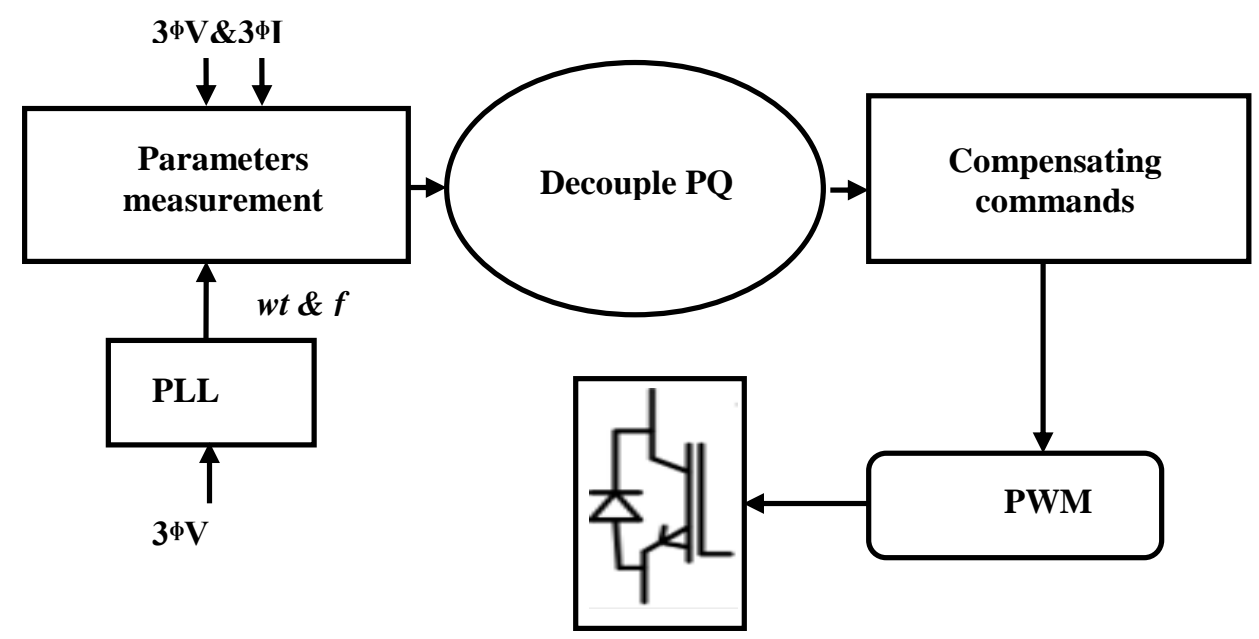

Figure 1. DSTATCOM block diagram control strategy

When a static synchronous compensator (STATCOM) is used in distribution systems, it is called distribution static compensator (DSTATCOM). It is used with a grid that has low or medium voltage. Its main configuration is similar as STATCOM but with a few modifications. The DSTATCOM is used to regulate voltage at the point of common coupling (PCC). This section gives an introduction of the DSTATCOM and its working principles. Its applications and several configurations are explained by some examples [4]. The control strategies are also discussed in this chapter. Figure 2 shows the basic structure of 
DSTATCOM. Figure 3 shows the components of DSTATCOM. The general configuration of DSTATCOM consists of the following components which are voltage source converter, energy storage device, coupling transformer, controller, L-C passive filter.

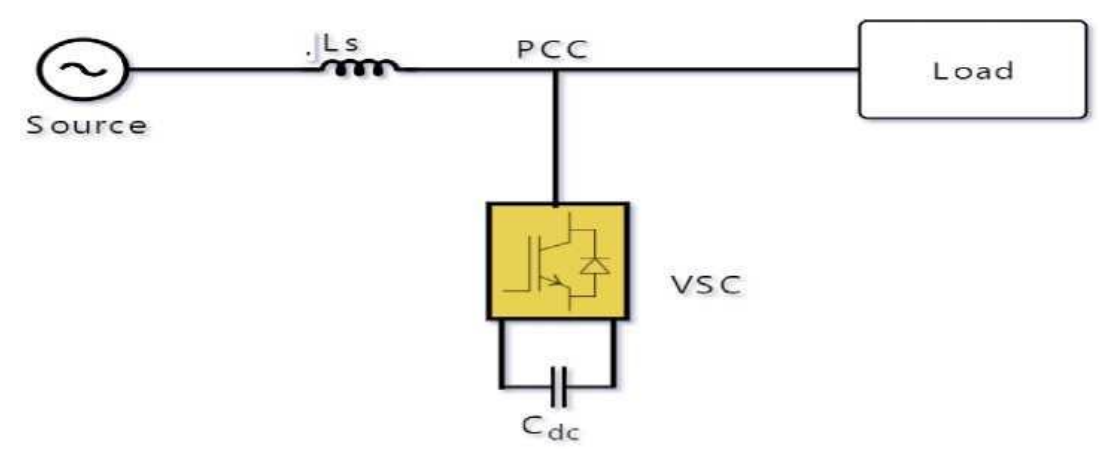

Figure 2. DSTATCOM structure connected to the grid

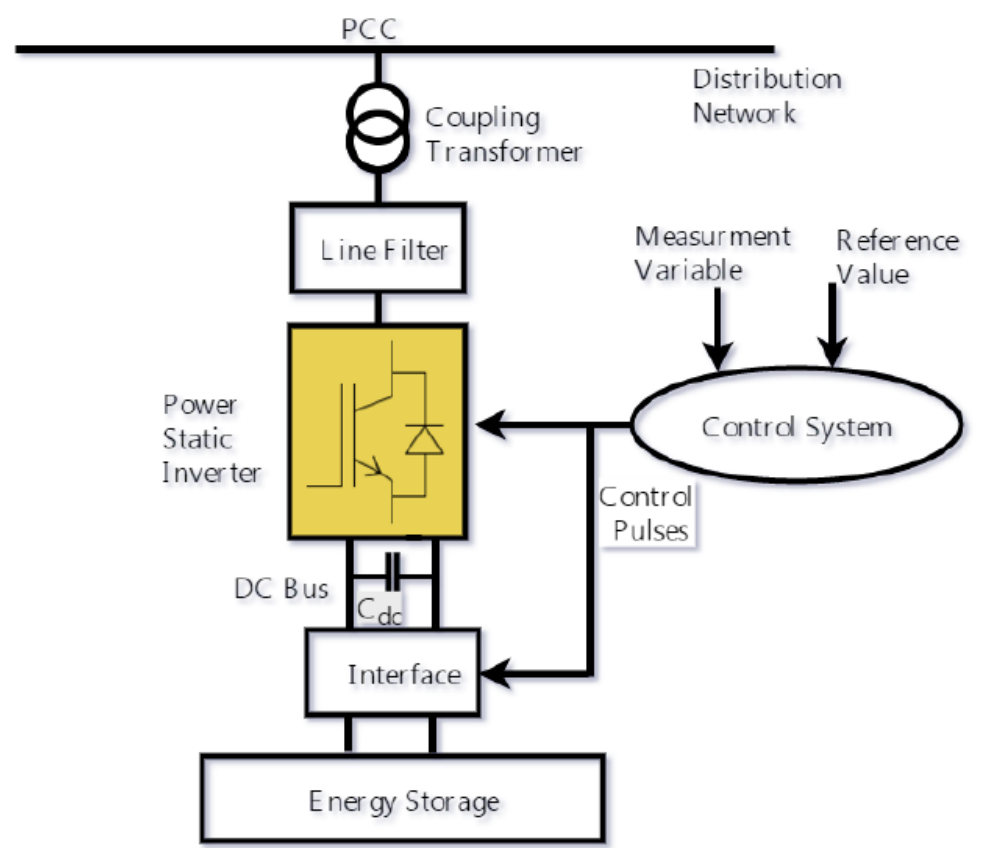

Figure 3. DSTATCOM components

\section{RESULTS AND DISCUSSION}

This scetion will describe how to solve the voltage issues in an urgent situation by providing reactive support from the DSTATCOM in the microgrid. The proposed DSTATCOM was installed in different locations in the Microgrid and the best location was chosen for the purpose of improved power quality and efficiency. Also, the dynamic behavior and performance of DSTATCOM to improve power quality in microgrid are discussed. The proposed DSTATCOM has been validated in the MG for different situations. Dynamic simulations have been carried out using MATLAB/Simulink as shown in Figure 4 and based on the parameters mentioned in Table 1. In the simulation, it is assumed that the Microgrid is connected to the grid where the voltage at the substation is programmed to be $1 \mathrm{pu}$. Two scenarios discussed in this chapter with and without DSTATCOM, three buses have been chosen; the first bus (675) is the weakest bus. The second one (680) is connected to the PV system in order to see the impact of the distribution generation (PV system) on the MG for different situations and to see how the DSTATCOM can improve the power quality in the microgrid. The third one (650) is connected to the grid nearest to the substation to see the effects from MG on the main grid. 
Table 1. Systems parameters

\begin{tabular}{ll}
\hline \multicolumn{1}{c}{ Name } & \multicolumn{1}{c}{ Value } \\
\hline Source Voltage & $4.16 \mathrm{kV}(1 \mathrm{PU})$ \\
Nominal Power & $3 \mathrm{MVAR}$ \\
DC link Capacitance $(\mathrm{Cp})$ & $20000 \mathrm{pF}$ \\
DC link Capacitance $(\mathrm{Cm})$ & $20000 \mathrm{pF}$ \\
Capacitor Voltage (Vdc) & $1700 \mathrm{~V}$ \\
PV parameters & \\
Max. Power Module & $315.07 \mathrm{~W}, 54.7 \mathrm{~V}, 5.76 \mathrm{~A}$ \\
Max Power For Two PVs & $200 \mathrm{KW}$ \\
Irradiance & $1000\left(\mathrm{~W} / \mathrm{m}^{2}\right)$ \\
Temperature & $25 \mathrm{C}$ \\
Switching Power frequency (fsw ) & $40 \mathrm{kHz}$ \\
Switching Control frequency (fsw ) & $10 \mathrm{kHz}$ \\
MPPT Controller & Based on the Perturb \& Observe algorithm \\
Microgrid Parameters & Value \\
Substation Voltage & $115 \mathrm{KV}$ \\
Transformer! & $5 \mathrm{MVA},(115 / 4.16) \mathrm{KV}$ \\
Transformed & $0.5 \mathrm{MVA},(4.16 / 0.48) \mathrm{KV}$ \\
Nominal source voltage (Vs) & $4.16 \mathrm{KV}(1 \mathrm{pu})$ \\
Nominal load power (PL and QL) & $3.25 \mathrm{MW}$ and 1.75MVar \\
Frequency (fs) & $60 \mathrm{~Hz}$ \\
\hline
\end{tabular}

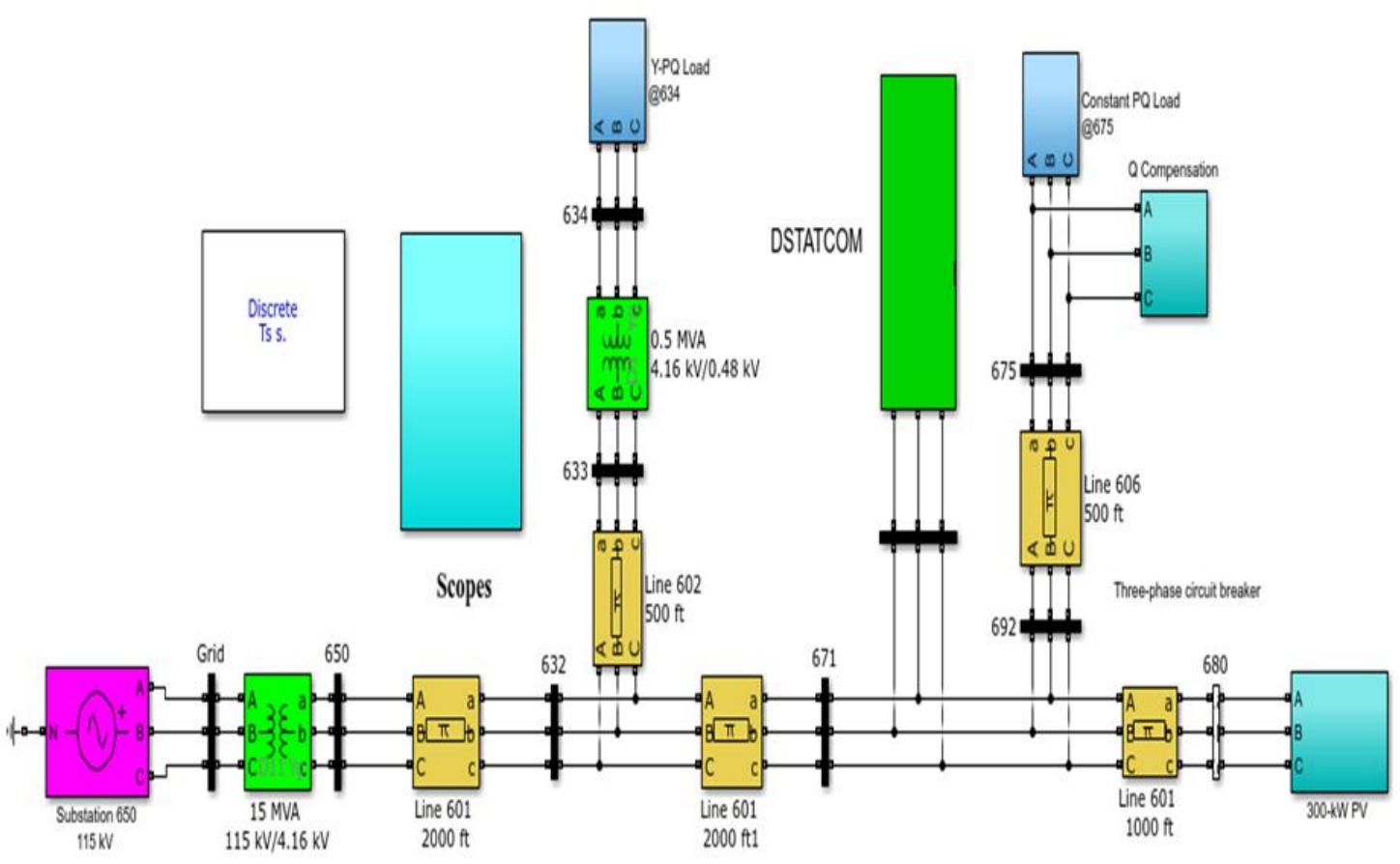

Figure 4. System simulink scheme

\subsection{Scenario 1: microgrid w/o DSTATCOM in case of voltage sag and swell}

In this scenario, the voltage for the microgrid was programmed to be sag and swell in certain seconds to see the effects on the microgrid. This scenario explains and discusses the benefits of using DSTATCOM and how it recovers the voltage after transit. The voltage magnitudes and waveforms, total harmonic distortion, and active and reactive power for the weakest bus (650) for two cases w/o DSTATCOM are shown in Figure 5. In the first case (microgrid without DSTATCOM) and at time $=0.4 \mathrm{~s}$, the sag voltage was programmed to be $0.8 \mathrm{pu}$ at the substation to drop the Microgrid voltage as low as 0.8 pu for a period of 0.2 seconds as shown in Figure 5. Then at $t=1 \mathrm{~s}$ the swell voltage was programmed to raise the voltage in the $\mathrm{MG}$ as high as $1.07 \mathrm{Pu}$ for 0.2 seconds. After a while, at $\mathrm{t}=1.6 \mathrm{~s}$ the sag voltage was programmed again for a period of 0.2 seconds to drop the voltage to be $0.92 \mathrm{pu}$. 


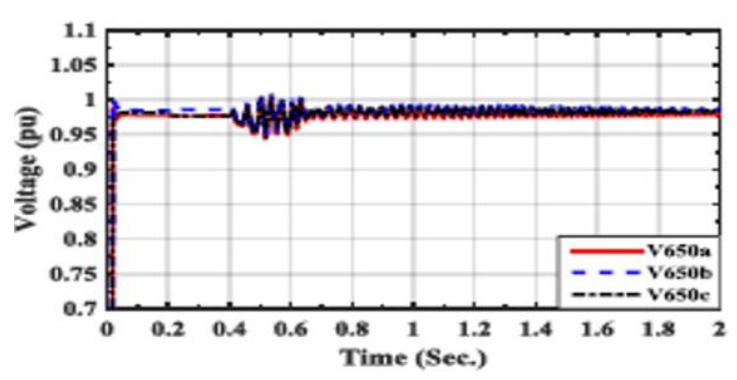

(a)

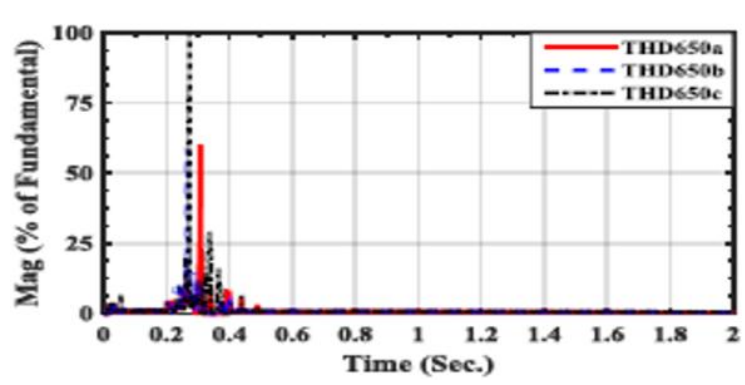

(c)

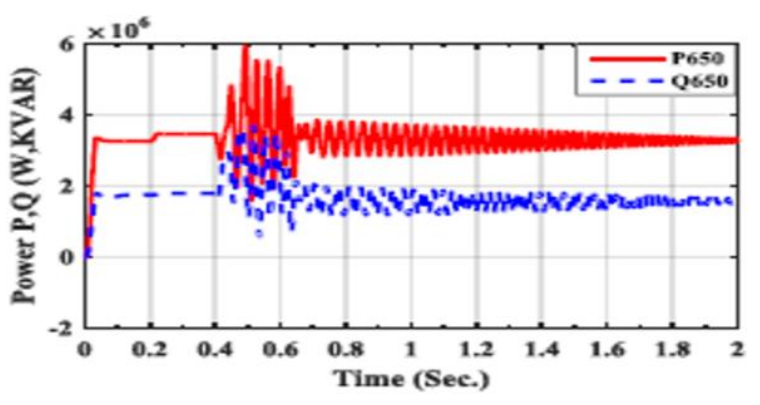

(e)

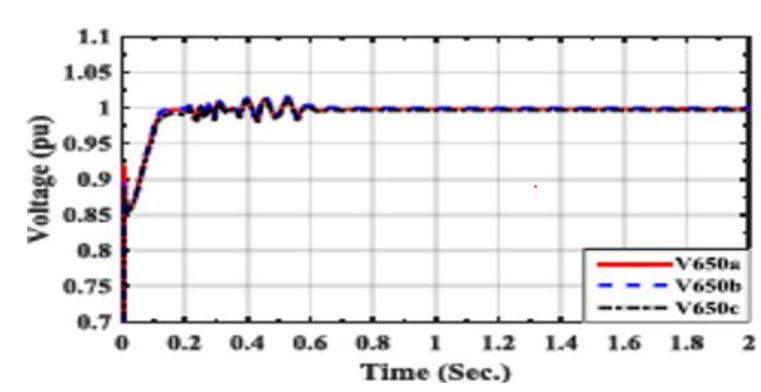

(b)

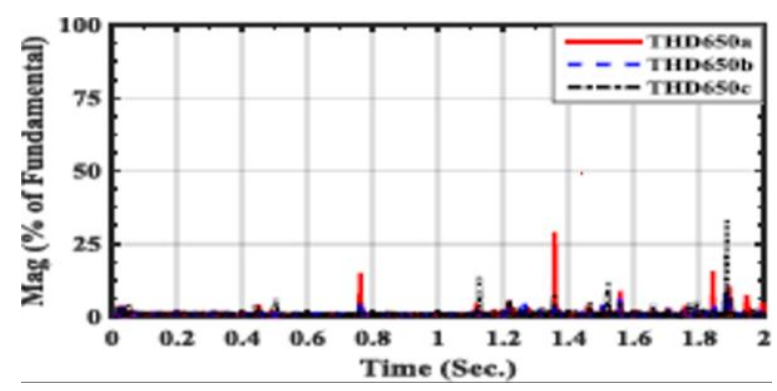

(d)

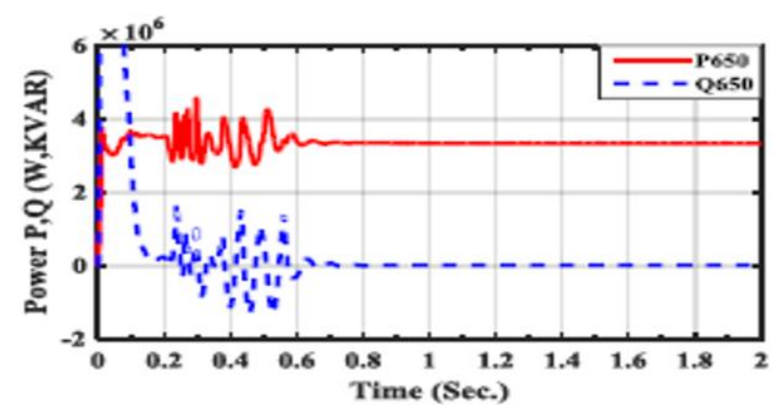

(f)

Figure 5. Voltage, THD, and power, for MG without and with DSTATCOM in case of PV system tripped and reconnected in a certain period at bus 650, (a) Voltages at bus 650 without DSTATCOM, (b) Voltages at bus 650 with DSTATCOM, (c) THD at bus 650 without DSTATCOM, (d) THD at bus 650 with DSTATCOM, (e) Active and reative power at bus 650 without DSTATCOM, (f) Active and reactive power at bus 650 with DSTATCOM

\subsection{Scenario 2: microgrid w/o DSTATCOM in case of PV system is tripped or reconnected}

In this scenario, the impact of distribution generations on the Microgrid is discussed. The possible solution to solve problems that happens in the Microgrid after isolating and reconnecting the DG (PV) during a certain period is demonstrated. The voltage for the MG has been programmed to be $1 \mathrm{pu}$, and the PV system has been isolated at $\mathrm{t}=0.2 \mathrm{~s}$ and reconnected at $\mathrm{t}=0.4 \mathrm{~s}$ to see what effects the PV system will has on the MG. This scenario is discussed and elucidates the merits of using DSTATCOM and how it retrieves the voltage after a transit occurs. The voltage magnitudes and waveforms, total harmonic distortion, and active and reactive power for the weakest bus (680) for two cases with and without DSTATCOM are shown in Figure 6. Appendix A illustrates this scenario at bus 650 and bus 680.

In the first case (microgrid without DSTATCOM), at $\mathrm{t}=0.2 \mathrm{~s}$, the PV is tripped from the microgrid, which means that $200 \mathrm{KW}$ are isolated from the Microgrid. This isolation will make a significant transit in the microgrid voltage. This transit will continue for a period of around 0.2 seconds. After that time, the PV will return to connect at $\mathrm{t}=0.4$, but now it will face a problem, which is that the voltage will be oscillating between $0.8-1.05 \mathrm{pu}$. The oscillating voltage will continue for a long period, as shown in Figure 6(a). These oscillating voltage and 
transits will produce harmonics, which will have the main impact on the power quality. Figures 6(c and e) show the total harmonics distortion and active and reactive power, respectively.

However, in the second case (microgrid with DSTATCOM), by connecting the proposed DSTATCOM to the microgrid, the DSTATCOM can supply reactive power to support the microgrid in the transit time. For instance, in this situation at $\mathrm{t}=0.2 \mathrm{~s}$ when the PV is isolated from the Microgrid, there still is a small transit, but it is significantly less that in the first case. After $t=0.4$, the PV system is reconnected, and the voltage starts oscillating between 0.9-1.05 $\mathrm{pu}$. The oscillating voltage will stop after $\mathrm{t}=0.6 \mathrm{~s}$, which is much more efficient than the case without DSTATCOM. Figures 6( $a$ and b) compare voltages in pu for three-phase at bus 680, in cases with and without DSTATCOM. By mitigating the oscillation voltage, the total harmonics distortion will be reduced as shown in Figure 6(d). Improving the voltage waveforms and magnitudes and minimizing the harmonics has a great impact on reinforcing the power quality, efficiency and reliability in the microgrid. Figure 6(f) shows how the DSTATCOM has improved the active and reactive power. As shown in Table 2, each sag and swell has an impact on the voltage magnitudes and waveforms, which results in generating harmonics. This will affect the power quality of the whole system, as shown in Figure 5.

In the second scenario, the proposed method can enhance the Microgrid voltage by providing and absorb reactive power. The device will recover the voltage to be at the accepted range between (0.94-1.06) pu based on IEEE standards. Table 3 shows that the DSTATCOM is recovering the voltage quickly, which eliminates THD by filtering the harmonics with transformer leakage reactance. Also, DSTATCOM has improved the Microgrid voltage resulting in power quality improvement.

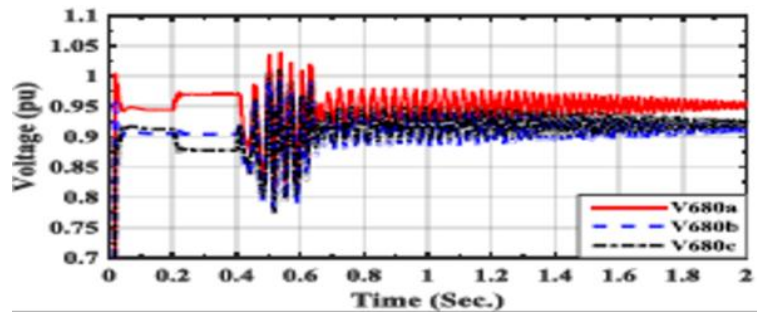

(a)

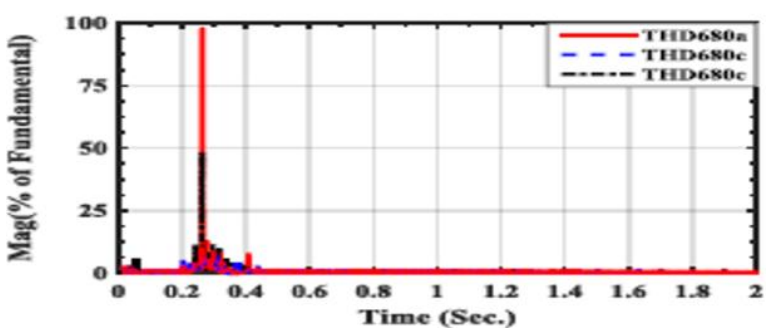

(c)

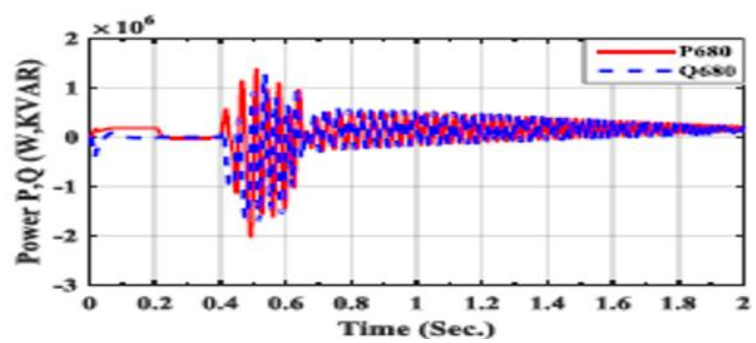

(e)

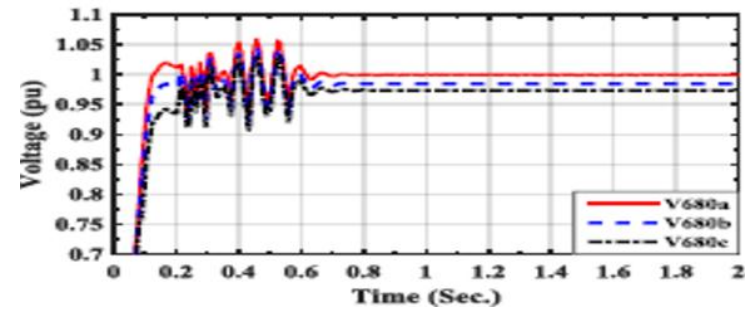

(b)

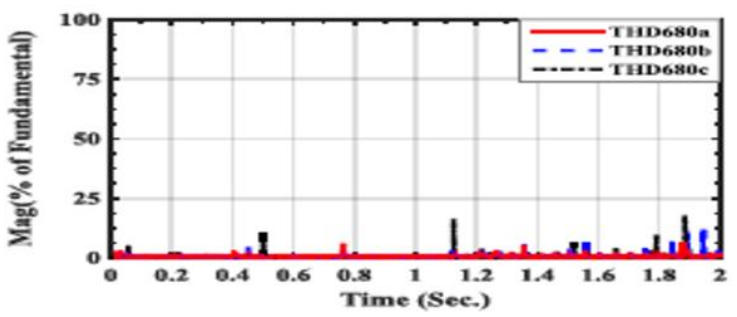

(d)

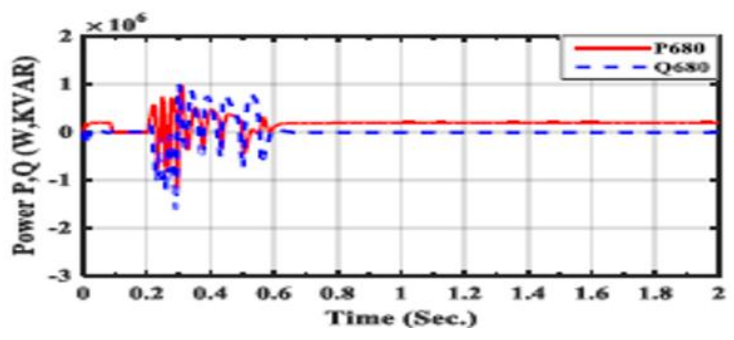

(f)

Figure 6. Voltage, THD, and Power, for MG with and without DSTATCOM in case of PV system tripped and reconnected in a certain period at bus 680, (a) Voltages at bus 680 without DSTATCOM, (b) Voltages at bus 680 with DSTATCOM, (c) THD at bus 680 without DSTATCOM, (d) THD at bus 680 with DSTATCOM, (e) Active and reactive power at bus 680 without DSTATCOM, (f) Active and reactive power at bus 680 with DSTATCOM 
Table 2. Voltage magnitudes for three-phase at bus 680 without DSTATCOM

\begin{tabular}{lcccc}
\hline Programmed voltage & Normal conditions 1 pu & Voltage sag 0.8 pu & Voltage swell 1.07 pu & Voltage sag 0.92 pu \\
\hline Phase A Voltage (pu) & 0.89 & 0.67 & 0.97 & 0.78 \\
Phase B Voltage (pu) & 0.95 & 0.69 & 1.03 & 0.85 \\
Phase C & 0.89 & 0.72 & 0.95 & 0.82 \\
\hline
\end{tabular}

Table 3. Voltage magnitudes for three phase at bus 680 with DSTATCOM

\begin{tabular}{lcccc}
\hline Programmed voltage & Normal conditions 1 pu & Voltage sag 0.8 pu & Voltage swell 1.07 pu & Voltage sag 0.92 pu \\
\hline Phase A Voltage (pu) & 0.95 & 0.89 & 0.97 & 0.95 \\
Phase B Voltage pu & 1 & 0.93 & 1.04 & 0.96 \\
Phase C Voltage (pu) & 0.94 & 0.9 & 0.98 & 0.94 \\
\hline
\end{tabular}

\section{CONCLUSION}

A 48-pulse voltage source inverter based DSTATCOM and its application, especially its operation during sag, swell, and DG's tripping and reconnecting during certain periods are presented in this thesis. To further understand and analyze DSTATCOM, the modeling of the IEEE 13-bus system, PV system, and the proposed DSTATCOM is studied. Validating the proposed DSTATCOM in different scenarios is carried out by using MATLAB/SIMULINK. The simulation results show the difference between the voltage in the Microgrid with and without DSTATCOM and demonstrate that the DSTATCOM can improve power quality in the Microgrid. It is shown that, by using the DSTATCOM, the power flow in the Microgrid can be managed, the total harmonics distortion can be alleviated, and the voltage profile can be regulated.

\section{REFERENCES}

[1] Douglas S. Dorr, Carl E. Becker, Christopher J. Melhorn et al., "IEEE Std 1100- 2005_Part1 (Revision of IEEE std 1100-1999)," IEEE Standard 1100 ${ }^{T M}-2005,2005$.

[2] M. G. Molina and P. E. Mercado, "Dynamic modeling and control design of DSTATCOM with ultra-capacitor energy storage for power quality improvements," 2008 IEEE/PES Transmission and Distribution Conference and Exposition: Latin America, Bogota, pp. 1-8, 2008.

[3] B. Singh, P. Jayaprakash, and D. P. Kothari, "New Control Approach for Capacitor Supported DSTATCOM in Three-phase Four wire Distribution System Under Non-Ideal Supply Voltage Conditions based on Synchronous Reference Frame Theory," International Journal of Electrical Power and Energy System, vol. 33, no. 5, pp. 1109-1117, 2011.

[4] P. Rao, M. L. Crow and Z. Yang, "STATCOM control for power system voltage control applications," in IEEE Transactions on Power Delivery, vol. 15, no. 4, pp. 1311-1317, Oct. 2000.

[5] B. Blazic and I. Papic, "STATCOM Control for Operation with Unbalanced Voltages," 2006 12th International Power Electronics and Motion Control Conference, Portoroz, pp. 1454-1459, 2006.

[6] H. Yonezawa et al., "Study of a STATCOM application for voltage stability evaluated by dynamic PV curves and time simulations," 2000 IEEE Power Engineering Society Winter Meeting. Conference Proceedings (Cat. No.00CH37077), Singapore, pp. 1471-1476 vol. 2, 2000.

[7] R. J. Nelson, J. Bian, D. G. Ramey, et al., "Transient Stability Enhancement with FACTS controllers," Sixth International Conference on AC and DC Power Transmission, London, UK, pp. 269-274, 1996.

[8] M. N. Kabir, Y. Mishra, G. Ledwich, Z. Y. Dong and K. P. Wong, "Coordinated Control of Grid-Connected Photovoltaic Reactive Power and Battery Energy Storage Systems to Improve the Voltage Profile of a Residential Distribution Feeder," in IEEE Transactions on Industrial Informatics, vol. 10, no. 2, pp. 967-977, May 2014.

[9] Z. Wang, H. Chen, J. Wang and M. Begovic, "Inverter-Less Hybrid Voltage/Var Control for Distribution Circuits With Photovoltaic Generators," in IEEE Transactions on Smart Grid, vol. 5, no. 6, pp. 2718-2728, Nov. 2014.

[10] K. H. Ali, "Voltage and Reactive Power Management in Microgrid," (Unpublished master's thesis), University of New Haven, New Haven, USA 2016.

[11] P. Richardson, D. Flynn and A. Keane, "Optimal Charging of Electric Vehicles in Low-Voltage Distribution Systems," in IEEE Transactions on Power Systems, vol. 27, no. 1, pp. 268-279, Feb. 2012.

[12] Z. Zhang, L. F. Ochoa and G. Valverde, "A Novel Voltage Sensitivity Approach for the Decentralized Control of DG Plants," in IEEE Transactions on Power Systems, vol. 33, no. 2, pp. 1566-1576, March 2018.

[13] H. Zhu and H. J. Liu, "Fast Local Voltage Control Under Limited Reactive Power: Optimality and Stability Analysis," in IEEE Transactions on Power Systems, vol. 31, no. 5, pp. 3794-3803, Sept. 2016.s

[14] D. J. Hanson, C. Horwill, J. Loughran and D. R. Monkhouse, "The application of a relocatable STATCOM-based SVC on the UK National Grid system," IEEE/PES Transmission and Distribution Conference and Exhibition, Yokohama, Japan, pp. 1202-1207, vol. 2, 2002.

[15] Zaid H. Ali, Ziyaad H. Saleh, Raid W. Daoud, Ahmed H. Ahmed“'Design and simulation of a microgrid for TIH campus," Indonesian Journal of Electrical Engineering and Computer Science (IJEECS), vol. 19, no. 2, pp. 729-736, August 2020. 
[16] P. Petitclair, S. Bacha and J. -. Ferrieux, "Optimized linearization via feedback control law for a STATCOM," IAS '97. Conference Record of the 1997 IEEE Industry Applications Conference Thirty-Second IAS Annual Meeting, New Orleans, LA, USA, pp. 880-885, vol. 2, 1997.

[17] P. Kumar and N. Prabhu, "Performance Analysis of Fuel Cell DSTATCOM," 2019 Fifth International Conference on Electrical Energy Systems (ICEES), Chennai, India, 2019.

[18] R. Pulikkal and K. Rathi, "PV supported DSTATCOM using Icos\& controller," 2015 International Conference on Power, Instrumentation, Control and Computing (PICC), Thrissur, pp. 1-5, 2015.

[19] Kavitha, M., Sivachidambaranathan, V., "Comparison of Different Control Techniques for Interleaved DC-DC Converter," International Journal of Power Electronics and Drive System (IJPEDS), vol. 9, no. 2, pp. 641-647, June 2018.

[20] N. Kumar, I. Hussain, B. Singh and B. K. Panigrahi, "Normal Harmonic Search Algorithm-Based MPPT for Solar PV System and Integrated With Grid Using Reduced Sensor Approach and PNKLMS Algorithm," in IEEE Transactions on Industry Applications, vol. 54, no. 6, pp. 6343-6352, 2018.

[21] C. Tareila, P. Sotoodeh and R. D. Miller, "Design and control of a single-phase D-STATCOM inverter for wind applications," 2012 IEEE Power Electronics and Machines in Wind Applications, Denver, CO, pp. 1-5, 2012.

[22] B. Singh, A. Adya, A. P. Mittal and J. R. P. Gupta, "Modeling, Design and Analysis of Different Controllers for DSTATCOM," 2008 Joint International Conference on Power System Technology and IEEE Power India Conference, New Delhi, pp. 1-8, 2008.

[23] Banerji, Ambarnath, Sujit K., Bhim Singh, "DSTATCOM Control Algorithms: A Review," International Journal of Power Electronics and Drive Systems (IJPEDS), vol. 2, no. 3, pp. 285-296, 2012.

[24] S. Sreejith, U. Bose, K. M. Divya Sree Vachana and V. Jyothi, "Application of D-STATCOM as load compensator for power factor correction," 2014 International Conference on Control, Instrumentation, Communication and Computational Technologies (ICCICCT), KanyakumariX, pp. 595-600, 2008.

[25] B. Singh, S. R. Arya, A. Chandra and K. Al-Haddad, "Implementation of Adaptive Filter in Distribution Static Compensator," in IEEE Transactions on Industry Applications, vol. 50, no. 5, pp. 3026-3036, 2014

[26] M. Barghi Latran, A. Teke and Y. Yoldaş, "Mitigation of power quality problems using distribution static synchronous compensator: a comprehensive review," in IET Power Electronics, vol. 8, no. 7, pp. 1312-1328, 2015.

\section{BIOGRAPHIES OF AUTHORS}
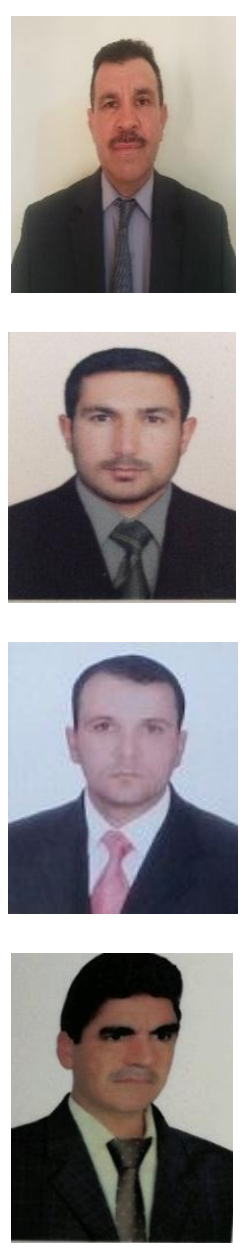

Ziyaad H. Saleh Ph.D in computer engineering, Currently, he is a Assist Prof. at Tikrit University-College of Petroleum and Minerals. He is Highly interested in renewable energy resources, communication systems His research experience includes nano-scale structures, artificial materials for novel electromagnetic applications. He has published many papers in international and local conferences and journals.

Zaid H. Ali: Currently, he is a lecturer at the Northern Technical University-Iraq. He holds MS.c degree from the University of New Haven, the USA in 2017 and received B.S. Degree in Electrical and Electronic Engineering from the University of Tikrit-Iraq in 2009. He is highly interested in renewable energy resources, Solar tracker systems, Wind turbines, Electrical power, Communication, Systems Engineering, Power Distribution systems, and digital signal processing (DSP). He has published many papers in local and international journals and conferences.

Raid W. Daoud: Bachelor college of Techniques computer engineering, Northern Technical University, Iraq, 2003, and the M.Sc from the same college in 2008. I have more than one paper published in different computer subjects, such as control and optical fiber.

Ahmed H Ahmed: born in Iraq-Kirkuk May-14-1981. MSc in Mechanical Engineering, Tikrit University, College of Engineering, Tikrit, Salah Aldeen, Iraq 2008. His interesting researches in the field of Thermo-fluid systems, Renewable Energies, Nano-fluid applications, Composite Materials and Water Distillation methods. Asst. Prof. Ahmed is a faculty member at Mechanical Power Department, Northern Technical University, Mosul and he is a member of Iraqi Engineering Union. 